University of Rhode Island

DigitalCommons@URI

2016

The Effects of Information on Public Attitudes Toward Renewable Energy

David Bidwell

University of Rhode Island, dbidwell@uri.edu

Follow this and additional works at: https://digitalcommons.uri.edu/maf_facpubs

The University of Rhode Island Faculty have made this article openly available.

Please let us know how Open Access to this research benefits you.

This is a pre-publication author manuscript of the final, published article.

Terms of Use

This article is made available under the terms and conditions applicable towards Open Access

Policy Articles, as set forth in our Terms of Use.

Citation/Publisher Attribution

Bidwell, D. (2016). The Effects of Information on Public Attitudes Toward Renewable Energy. Environment and Behavior, 48(6): 743-768.

Available at: http://dx.doi.org/10.1177/0013916514554696

This Article is brought to you for free and open access by the Marine Affairs at DigitalCommons@URI. It has been accepted for inclusion in Marine Affairs Faculty Publications by an authorized administrator of DigitalCommons@URI.For more information, please contact digitalcommons-group@uri.edu. 


\title{
The Effects of Information on Public Attitudes towards Renewable Energy
}

\author{
Abstract \\ The information-deficit model is a common framework for explaining public attitudes towards new \\ technologies, including renewable energy technology. This model assumes that public opposition to \\ technology is based on a lack of quality information. The siting of facilities such as commercial wind \\ farms frequently face opposition from residents of local communities, despite broad public support for \\ renewable energy. Although social science has been critical of the information-deficit model, providing \\ information to the public can influence both the substance and quality of attitudes. In this study, \\ residents of coastal communities in Michigan, supportive of wind energy on average, were provided in- \\ depth information about wind energy. Compared to a control group, participants who attended \\ information sessions exhibited greater change in both their general support for wind energy and the \\ strength of those attitudes. Possible implications for the siting of wind farms and other renewable \\ projects are discussed.
}

\section{Introduction}

Renewable energy advocates frequently characterize public opposition to renewables projects in terms consistent with the "information-deficit model" (deficit model, for short). The deficit model is a conventional perspective on public attitudes and behavior, which explains public viewpoints as resulting from a lack of knowledge. The corollary to this perspective is that providing information to the public will change attitudes and behavior. Social science, however, has criticized the deficit model in recent decades, and research has demonstrated that the correlation of knowledge and attitudes is less than perfect. This does not, however, mean that information does not play an important role in attitude 
formation and change. In particular, the provision of information and the resulting knowledge (real or perceived) can change the quality of attitudes, namely the strength with which attitudes are held.

In this article, I discuss the deficit model and the influence of information on attitudes towards a particular form of renewable energy generation, large-scale wind farms. By comparing attendees of an information session on wind farms with a control group, the research reported in this article provides evidence that receiving information can contribute to a change in attitude. In a small sample of residents of coastal Michigan, participants in an information session exhibited a rise in enthusiasm for wind farms in a follow-up survey. More importantly, perhaps, participants in those events also demonstrated a rise in confidence with which they held those attitudes. Implications for the role of information in the siting of wind farms and other renewable energy developments are discussed.

\section{The Deficit Model}

At its core, the deficit model holds that public attitudes or behaviors can be explained by a deficiency in knowledge (Gross, 1994). The study of environmental attitudes and behavior has examined the role of general and issue-specific knowledge in shaping views and actions (Kollmuss \& Agyeman, 2002; Schahn \& Holzer, 1990; Schultz, 2002). Research shows that information can make a difference in some circumstances, but it is often insufficient to elicit desired behaviors (Schultz, 2002). Two recent articles (Howell, 2014; Nolan, 2010), for example, examine the knowledge-deficit framework by studying the effects of attending movies intended to heighten concern about climate change. Howell found that while receiving information through the film media increased concern about the issues, those effects on attitudes were not long-lasting. Nolan also demonstrated that viewing a movie could boost concern, as well as intention to act, but it did not result in actual behavior change.

The knowledge-deficit model is a central concept to the study of public understanding of science (PUS), a field concerned with the relationship between general scientific knowledge and public views of 
science and technology. The PUS field has shown that deficit-model thinking underlies many experts' views on public opposition to new technologies (Bauer, Allum, \& Miller, 2007; Sturgis \& Allum, 2004), leading them to believe that support for a technology can be garnered through information and education about the technology and its potential impacts (Nisbet \& Scheufele, 2009; Ziman, 1991). While most PUS work focuses on the role of general scientific literacy in forming attitudes, some research has also examined the role of issue-specific knowledge (Sturgis, Cooper, \& Fife-Schaw, 2005). The deficit model has been roundly criticized in this field (Bauer et al., 2007; Owens, 2000; Sturgis \& Allum, 2004; Sturgis et al., 2005) for providing too narrow a view on public viewpoints and failing to consider the psychological, social, and institutional contexts of attitude formation (Nisbet \& Scheufele, 2009; Owens \& Driffill, 2008).

However, Sturgis and Allum (2004) and others have encouraged a second look at the role of knowledge and information in shaping attitudes. They note that empirical studies generally find that knowledge does, in fact, have an important influence on attitudes. Rather than ignoring the role of scientific knowledge, it is better to view information as insufficient for changing minds or behavior (Owens, 2000). Some recognize that while greater scientific knowledge is not necessarily "a lever of positive attitudes," knowledge affects the quality of those attitudes (Bauer et al., 2007; Evans \& Durant, 1995). In other words, while greater knowledge about an issue might not lead to desired behaviors or attitudes, it does change how people think about that topic and associated issues.

The idea that providing information to a person can change the quality of his or her attitudes is consistent with the study of public attitudes by social psychology. Social psychologists acknowledge that all attitudes are not created equal (Krosnick \& Abelson, 1992; Visser, Bizer, \& Krosnick, 2006). Some attitudes expressed by people are little more than top-of-the-head responses (Lindeman, 2002; Zaller \& Feldman, 1992), supported by little knowledge or cognition. These weak points of view are generally fleeting and easily changed (Bassili, 2008). On the other hand, some attitudes are held quite firmly. They 
exhibit a well-developed structure, with well-established cognitive pathways. Social psychologists refer to these attitudes as strong. Strong attitudes are described as sharing four features (Crano \& Prislin, 2006; Krosnick \& Petty, 1995; Lavine, Huff, Wagner, \& Sweeney, 1998; Petty, Haugtvedt, \& Smith, 1995): 1) greater persistence of the attitude over time; 2 ) resistance of the attitude to change; 3 ) greater impact of the attitude on other judgments; and 4) greater consistency between attitudes and behavior. Krosnick and Abelson (1992) use the term "crystallization" to describe strong attitudes: "numerous studies have shown that strong attitudes are in fact more firmly crystallized and have more impact on cognition and behavior than weak attitudes" (178).

Knowledge is one path to a stronger attitude (Krosnick \& Petty, 1995; Prislin, 1996; Visser et al., 2006). Research has shown that perceived knowledge or actual thoughtful consideration of an issue leads to stronger attitudes (Barden \& Petty, 2008; Petty et al., 1995). Note that it is not necessary to have actual deep knowledge about a subject to have a strong attitude towards it; believing you are knowledgeable is enough to strengthen attitudes. Likewise, just the perception of greater elaboration (i.e., belief you have given thought to an issue) is enough to strengthen attitudes about that issue (Petty, Haugtvedt, and Smith 1995a). This explains the qualitative difference in attitudes that are supported by knowledge or by information received. When a person receives information about a topic, or has an opportunity to consider and discuss that topic, his or her attitude towards that topic can become more crystallized.

\section{Attitudes towards Wind Energy and other Renewables}

Public opinion on renewable energy and subsequent support or opposition of specific technologies is a subject of growing interest among environmental social scientists. Opinion surveys indicate that public attitudes towards renewable energy technologies (renewables) are largely positive (Ansolabehere \& Konisky, 2009; Ek, 2005), with renewables commonly viewed as a partial solution to 
three societal challenges: meeting the growing demand for energy, ensuring energy security, and reducing harmful air emissions (Szarka, 2006). However, advocates have been frustrated by a presumed "social gap" between broad public support for renewables and the slow deployment of specific technologies (Bell, Gray, \& Haggett, 2005; Parks \& Theobald, 2011). Local opposition to specific projects is widely viewed as a significant obstacle to the broader adoption of renewable technologies (DevineWright, 2008, 2011; Kasperson \& Ram, 2013; Pasqualetti, 2011; Walker, Cass, Burningham, \& Barnett, 2010; Wüstenhagen, Wolsink, \& Bürer, 2007), even if public attitudes explain only part of the success or failure of the siting of renewable projects (Tuler, Ram, \& Kasperson, 2014).

Perhaps because the technology is more common than other renewables and has been the center of public disputes across Europe and the U.S. (Devine-Wright, 2008), the literature on public acceptability of renewables focuses heavily on large-scale wind energy developments. This literature primarily has sought to explain the gap in general public attitudes towards wind energy and community attitudes towards specific projects. Here, I review six perspectives. The first four are offered by Bell and colleagues (Bell et al., 2005; Bell, Gray, Haggett, \& Swaffield, 2013): the power of vocal minorities, selfinterested NIMBY responses, protection of valued places, and conditional support for wind energy. All four assume that general support for renewables and wind energy is genuine and that the social gap exists due to a lack of support for specific projects. None of these explanations is mutually exclusive, and it is likely that the totality of community opposition is comprised of a mix of perspectives (Bell et al., 2013).

One potential reason for the gap in attitudes and project deployment is that a vocal minority, opposed to wind energy technology, dominates the decision process in communities. Bell et al (2005) refer to this as the "democratic deficit" explanation. The assumption underlying this explanation is that a small number of opponents in a community are able to dominate the public conversation about an issue and influence siting decisions. There are, in fact, individuals who will reject wind energy and other 
renewables as a matter of principle, and their reasons for opposing these technologies may be very central to their personal identities. Research indicates that opposition to wind farm development is fueled, in part, by general conservatism undergirded by "traditional" values (Bidwell, 2013).

Another explanation holds that self-interest leads individuals who are generally supportive of renewables to oppose the construction of projects in or near their community. This explanation is generally known as NIMBY (not in my backyard). The NIMBY label is commonly used as a pejorative, implying that people put their personal interests ahead of societal benefits (Wolsink, 2007). Many social scientists have dismissed the NIMBY explanation as shortsighted, noting that public support for wind farms and other renewables is complex and multifaceted (Devine-Wright, 2011; Devine-Wright, 2004, 2009; Kempton, Firestone, Lilley, Rouleau, \& Whitaker, 2005; Swofford \& Slattery, 2010; Van der Horst, 2007; Wolsink, 2000). Wolsink (2007) provides the clearest evidence, showing that measures of NIMBY dimensions are not strong predictors of support or opposition in European studies. This is not to say that there are not some people who oppose wind energy developments based on narrow self-interest (Bell et al., 2013), but it does not account for all opposition.

Bell et al (2013) offer a third explanation focused on public attitudes towards the particular site for which a project is proposed. They refer to this as the "place protector" explanation: “...the place protector opposes a local development because of the value that she sees in that particular place while not seeing the same value or remaining agnostic on the value of other places where developments might take place." Evidence suggests that renewable projects are considered a threat to community members' place-based identities (Cass \& Walker, 2009; Devine-Wright, 2009). This perspective differs from NIMBY, in that people are seeking to protect the perceived inherent value of a location, rather than a self-interest.

A fourth possible contributor to the social gap is conditional support for wind energy. According to Bell et al (2005), "Most of the people who support wind energy do not support it without 
qualification" (463). In other words, people support the general ideas of renewables and wind energy but only if specific projects meet particular criteria. This explanation differs from NIMBYism and place protection in that those exhibiting conditional support would oppose wind energy developments that don't meet their criteria for approval wherever they are proposed (i.e., not just in their own community). Much of the recent literature focuses on this explanation, seeking to understand the factors that influence the conditional support of wind farm project (Bell et al., 2013). Researchers have identified several reasons for local opposition to proposed projects, including the perceived effects of wind farms on the landscape, the fairness of development processes and outcomes, and conflicts of underlying values among stakeholders (Bell et al., 2005; Devine-Wright, 2004; Ellis, Barry, \& Robinson, 2007; Firestone \& Kempton, 2007; Toke, Breukers, \& Wolsink, 2008; Wolsink, 1989).

Overall, frustration over perceived inconsistency between general and specific attitudes towards wind farm development is fueled by the assumption that specific attitudes are-or should be-shaped by positive general attitudes. The standard view of support for wind power can be characterized as a statement of conditional logic (if A, then B). Positive attitudes towards wind energy form the antecedent (A), and support for specific wind energy developments (i.e., wind farms) are the consequent (B). From this perspective, the social gap contradicts a rule of logic. The four explanations above follow this conditional logic, focusing on why a pro-renewables public opposes specific projects. In framing the gap in this manner, authors support the notion that specific attitudes should flow from general beliefs, and that an incongruity between general and specific attitudes is problematic, or even deviant (Aitken, 2010).

A fifth and sixth explanations for the social gap reject this conditional logic. Johansson and Laike (2007) and Wolsink (2012) state that attitudes towards wind energy in general and attitudes towards specific projects will understandably differ, as they are different attitude objects. Each carries a different set of associations in the minds of community members. Where people may consider issues such as 
energy security and environmental quality when thinking about wind energy in general, they think about specific impacts-e.g., noise, construction traffic, and a changed landscape-when a wind farm is proposed in or near their community. Wolsink (2012) provides a very insightful table that delineates the essential characteristics and attributes associated with wind energy systems in general versus those associate to a specific project. It is unrealistic, these authors argue, to expect consistency across these attitudes. Wolsink expresses a strong position on this, stating: "A clear correlation between general national public opinion and local decision making is theoretically not supported" (2012, p. 12229). While it is true that the general concept of wind energy would stir very different thoughts than a specific project, it is imprudent to assume that general attitudes towards wind energy would have no influence on responses to specific proposals. In fact, in a study of public attitudes in potential wind energy development sites in the United Kingdom, Jones and Eiser (2009) found that general attitudes towards renewables were a strong predictor of attitudes towards specific projects.

This brings us to a sixth, alternative perspective on the social gap. Van der Horst (2007) proposes that general public support "would merit some closer explanation" (Van der Horst, 2007, p. 2711). Perhaps, suggests Van der Horst, general attitudes are often too weak to have substantial influence on local attitudes when a wind farm project is proposed. This is a different perspective on the logic of the social gap, because it places some responsibility for the gap on the antecedent (general attitudes) rather than looking entirely to the consequent (responses to a wind farm proposal). This means that scholars should revisit general attitudes in an effort to develop a deeper understanding of fundamental views towards wind energy development. This shift in perspective also has important ramifications for how to close the social gap. Instead of focusing all attention on the wind farm development process, it suggests that the gap in public support for renewables could be reduced by strengthening general support for wind energy and other renewables. 


\section{Information and Renewable Energy Attitudes}

The notion that information campaigns or opportunities for public deliberation could reduce the social gap is relatively common. According to Bell et al. (2005), wind energy advocates have two possible responses to conditional support: change the projects or change people's minds. The latter option, changing minds, is a common approach in wind farm development, and information campaigns are a prevalent tool for pursuing this goal. There is a reasonable logic to information campaigns, since much of the public has limited awareness of renewable technologies (Walker, 1995).

Wind energy advocates envision attitudes towards wind energy projects becoming more positive as the public learns more about the benefits of wind energy and misconceptions about impacts are corrected. In interviewing a variety of actors in the development of renewable energy projects, Cass and Walker (2009) found ample evidence of information deficit perspectives. In their study, proponents of development felt that some opposition was caused by incorrect information spread by opposition groups and that providing correct information would lead to greater public support. Parks and Theobald (2011) found a similar stream of thought among wind energy advocates. The idea that information can create greater support for wind energy projects has been advocated by multiple authors as well (Jones \& Eiser, 2009; Kaldellis, 2005; Krohn \& Damborg, 1999; Strachan \& Lal, 2004). Owens and Driffill (2008), however, warn that there is a chance that informational interventions intended to increase support for a proposed energy project can actually backfire, due to public mistrust of the communicators providing the information.

Still, some scholars writing about public acceptance of wind farms have criticized explanations for the social gap that ascribe public opposition to a lack of knowledge (Ellis, Cowell, Warren, Strachan, \& Szarka, 2009; Haggett, 2011; Wolsink, 2011) and informational interventions intended to raise support for projects (Aitken, 2010; Bell et al., 2005; Jones \& Eiser, 2009). They point to evidence from social science research that multiple factors underlie support and opposition to wind energy developments, 
concluding that a knowledge-deficit model of opposition is too narrow. Moreover, the portrayal of opponents as ignorant or poorly informed delegitimizes their beliefs and values. If a project supporter believes that opposition is based in ignorance or misinformation, these authors claim, he or she will show less respect for the needs and values of those who oppose the project.

Despite these objections, I believe it is imprudent to ignore the potential effects of information campaigns and increased knowledge on public attitudes. Rather, it is important to understand how providing information to stakeholders affects attitudes towards renewable energy projects, in order to inform choices about the role for informational interventions in siting processes. The research presented here seeks to better understand the role of information in changing attitudes towards wind energy, in general, and the quality of those attitudes. This article examines how participation in an informational session on wind farms affects the attitudes of residents in communities where the development of commercial wind farms is possible but where specific projects have not yet been proposed. Based on the theoretical foundations of attitude strength and the role of perceived knowledge, two main hypotheses are tested: 1 ) Providing information to members of the public can affect their general attitudes towards wind energy, and 2) Participation in an information session may strengthen general attitudes towards wind energy.

\section{Study Methods}

This article reports findings from a study of attitudes towards the potential development of commercial wind farms in coastal Michigan. Interest in wind energy development in the State of Michigan has risen sharply in recent years, particularly in areas along the Great Lakes' coasts. A primary driver of this development pressure is a renewable portfolio standard (RPS), passed in to law in 2008, which required that 10 percent of electricity sold in the state come from renewable sources by 2015 . 
In 2009, Michigan Sea Grant provided funding to the Land Policy Institute (LPI) at Michigan State University to conduct an integrated assessment of issues related to siting wind farms in coastal areas of the state. To narrow the geographic scope of this assessment, three study areas were selected: Bay County, Presque Isle County, and a four-county area of the Upper Peninsula. Bay County is a relatively dense and urbanized area located at the base of Michigan's "thumb" which forms the Saginaw Bay of Lake Huron. The population of Bay County is 107,000, a third of which lives in Bay City. Presque Isle County sits in the northeast corner of Michigan's Lower Peninsula. A rural county of 13,400 people, its largest population center is the small town of Rogers City. The study area in the Upper Peninsula comprises four counties--Marquette, Baraga, Houghton, and Keweenaw-that frame the Keweenaw Bay of Lake Superior. This area of Michigan is largely rural and forested, with two population centers around the cities of Houghton and Marquette. The total population of the four counties is roughly 112,000 . These areas were selected to represent a diversity of geographic and demographic conditions. At the time of this study, no projects had been officially proposed within any of the three areas. Bay County, however, is just across Saginaw Bay from Huron County, which hosts the largest extant wind farm in the state.

Data reported in this study comes from three activities: a mail survey of a random sample of residents in the study areas, an identical survey administered to a convenience sample that participated in one of four information sessions, and a follow-up mail survey of all participants. The surveys consisted of closed-end questions centered on attitudes towards commercial wind farm development. Most of the questions asked respondents to consider how they would feel about a commercial wind farm development in or near their community, defined as the township, village, or city in Coastal Michigan where they live during all or part of the year. Questions were also asked to gauge the strength with which the respondents held their attitudes towards wind farms.

\section{Preliminary Mail Survey}


As part of a broader study on public attitudes towards wind energy Bidwell (2013), an eightpage mail survey was sent to 300 households in each of the three study areas (900 total surveys mailed) in early 2010. The cover letter indicated that this was a research project being conducted by LPI at Michigan State University and asked that the survey be completed by the adult with a birthday closest to a specific date. Following components of the tailored design method (Dillman, Smyth, \& Christian, 2009) households in the sample were sent reminder post cards and replacement surveys to increase the response rate. After removing nonviable addresses, the total sample for this study was 827 households. With 375 completed surveys, the response rate was 45.3 percent. These responses serve as a control group for this study.

Four to six weeks following receipt of the initial survey, an abbreviated form of the original survey was sent to respondents from the control group. This survey consisted of all the original attitudinal and attitude strength measures, minus questions about personal characteristics. The surveys included unique identifying codes to allow easy comparison of preliminary and follow-up responses. Of 375 initial control group respondents, 171 viable follow-up surveys (46 percent) were received. Therefore, the final rate of response for the two-wave, control survey was 20.7 percent.

\section{Informational Events}

Informational events were held in four locations: Hancock (Houghton County), Marquette (Marquette County), Rogers City (Presque Isle County), and Bay City (Bay County). Two events were held in the Upper Peninsula, due to large distances covered by that study area. Invitations to the events were mailed to a separate random sample of 300 residents in each study area (900 total invitations); however, due to very low participation rates, the participants are not a representative sample of the study areas. A few residents also attended after learning of the events through word of mouth. Therefore, the participants in these events are considered a convenience sample. A total of 60 individuals participated in the events. 
Upon arrival, each participant was provided a packet containing an illustrated issues booklet, a county-specific map of wind resources and data, an explanation of informed consent, and the same eight-page survey of attitudes towards commercial wind farm development that had been mailed to the control group. Each event began with an introduction to the project and the review of a statement regarding informed consent to participate in a research project. Participants were then provided approximately 15 minutes to complete the survey.

The majority of the event was dedicated to reviewing the issues booklet. A Land Policy Institute specialist in renewable energy led this review. Opportunities to ask questions or provide comments were provided throughout the presentation.

The issues booklet was developed by the Land Policy Institute and refined through initial meetings with municipal officials and other stakeholders from the study areas. The booklet and presentation consisted of four sections: (1) wind farm basics, (2) wind energy development pressures, (3) the wind farm siting process, and (4) the effects of wind farms. The first section introduced participants to wind energy, the transmission and distribution electrical grids, and the basic components of a generic wind turbine and commercial wind farm. The second section provided a context to the pressures for wind energy development in Michigan, including an overview of the electricity market, wind resources, current and proposed wind energy systems in the state, and the renewable portfolio standard. The next section presented a 10-step wind farm siting and development process (adapted from a fact sheet by the American Wind Energy Association), and a summary of federal and state regulations that affect the location of wind farms. The final section of the booklet and presentation discussed potential effects of commercial wind farm developments. These include visual effects, noise, shadow flicker, impacts to birds and other wildlife, effects of construction, effects to home values, and other projected tax base and other economic effects. This section also included a brief introduction to local zoning authority in Michigan and examples of wind-farm related ordinances. 
The presentation concluded with a review of a map showing the location of commercially viable wind resources in the county (as determined by a GIS-based computer model developed by LPI).

Four to six weeks following the event, participants were mailed the abbreviated follow-up survey by mail. As with the control group, surveys included an identification code to facilitate the comparison of preliminary and follow-up responses. The 60 events participants returned 28 viable follow-up surveys (47 percent of the original participants and 3 percent of the 900 originally invited).

\section{Measures}

The following section explains the measures that were constructed to capture the study participant's general attitudes towards wind farms and the strength with which they held those attitudes.

\section{General Attitudes towards Wind Farms}

Based on questions in the 2008 Massachusetts Institute of Technology Energy Survey, respondents were asked to use a five-point scale (strongly disagree to strongly agree) to rate their level of support or opposition to the construction of three types of electricity-generating facilities (coal-fired power plant, nuclear power plant, and commercial wind farm) in or near their community. Following Firestone and Kempton (2007), respondents were also asked to indicate the degree to which they would encourage or discourage construction of a commercial wind farm in or near their community.

Respondents also indicated the degree to which they would support certain actions to be priorities of Michigan policy makers. These priorities included support for other forms of wind energy (off-shore and community-scale).

Exploratory factor analysis of these measures revealed, and confirmatory factor analysis verified, a latent variable that I call wind enthusiasm. Four items, including support for commercial wind farms as a source of electricity and support for development of wind farms in or near one's community, 
as well as support for offshore wind farms and community-owned wind farms, formed a reliable (Cronbach's $\alpha=0.865)$ single factor (Table 1 ).

$<$ Table 1 here $>$

\section{Attitude Strength}

The measurement of attitude strength is not simple, and a variety of measurements are available in the literature. A growing consensus views attitude strength not as a single factor, but a suite of potential constructs including personal importance, certainty, perceived knowledge, and cognitive elaboration. Best practices in social psychology suggest the construction of measurement scales using relevant items on a per-study basis (Bassili, 2008; Krosnick \& Petty, 1995; Visser et al., 2006).

The surveys included five Likert-style items (five-point scale, strongly disagree to strongly agree) on attributes of attitude strength. These measures were based on questions used in previous social psychological studies (Barden \& Petty, 2008; Boninger, Krosnick, \& Berent, 1995; Pomerantz, Chaiken, \& Tordesillas, 1995). Exploratory and confirmatory factor analysis revealed a four-item latent factor including two measures of perceived knowledge about wind farms, one measure of certainty, and one measure of thoughtfulness (Table 1). This latent factor, which I label confidence, also exhibits high reliability (Cronbach's $\alpha=0.809)$.

\section{Results}

Because this study asked participants to complete both a preliminary and follow-up survey, selfselection of participants is a concern. Similar to other studies of public attitudes towards energy sources, control group respondents exhibited a high degree of general support for wind energy. To better understand potential biases of control group respondents who completed the follow-up survey, their mean ratings of wind enthusiasm and confidence were compared statistically. Mean ratings of wind enthusiasm among those completing only the initial survey $(M=3.84, S D=1.09)$ were not significantly 
different $(t[326]=1.306, p=.192)$ from initial wind enthusiasm ratings of respondents who returned the follow-up survey $(M=3.99, S D=.938)$. Also, mean confidence scores of those completing only the initial survey $(M=2.87, S D=.862)$ were not significantly different $(t[329]=1.245, p=.214)$ from the initial confidence ratings of those who completed the follow-up survey $(M=2.99, S D=.796)$.

The remainder of these analyses are confined to participants who completed both the preliminary and follow-up surveys.

\section{Comparison of Control Group and Events Participants}

Statistical tests were used to compare characteristics of the respondents of the mail survey (control group) and participants in the events. There were no statistically significant differences in gender $(t[192]=1.435, p=.153)$, educational attainment $(t[195]=-1.250, p=.213)$, or income $(t[177]=-.547$, $p=.585$ ) between the control group and event participants.

Individual items were summed and averaged for each latent variable, and t-tests were used to compare the mean ratings of events participants to those of the control group (table 2). Average support for wind energy was quite high among both the control group and event participants in this study. Event participants had somewhat higher preliminary ratings of wind enthusiasm $(M=4.21, S D=.78)$ than members of the control group ( $M=3.98, S D=.94)$; however, this difference is not statistically significant $(t[197]=-1.23, p=0.220)$. Initial ratings of confidence were significantly higher $(t[197]=-1.95$, $\mathrm{p}=.052)$ among event participants $(\mathrm{M}=3.30, \mathrm{SD}=.87)$ than control group members $(\mathrm{M}=2.98, \mathrm{SD}=.80)$. These differences are not surprising, given the self-selection of information session participants.

Differences between the control group and events participants were significant on responses to the follow-up survey. Follow-up wind enthusiasm ratings of events participants $(M=4.29, S D=.49)$ were significantly $(t[197]=-2.17, p=.032)$ higher than those of the control group ( $M=3.85, S D=1.07)$. Likewise, events participants had significantly higher $(t[197]=-2.81, p=.005)$ levels of confidence $(M=3.42, S D=.72)$ than the control group $(\mathrm{M}=2.99, \mathrm{SD}=.75)$ in the follow-up survey. 
$<$ Table 2 here>

Preliminary vs. Follow-up Scores on Wind Enthusiasm

In order to assess change in attitudes, a stepwise linear regression model was developed to determine the effects of preliminary attitudes and events participation on follow-up attitudes (table 3). Follow-up wind enthusiasm ratings served as the dependent variable. As expected, preliminary attitudes were a significant predictor of follow-up attitudes $(B=.945, p<.001)$, explaining more than 71 percent of the variance in follow-up attitudes $\left(R^{2}=.712, F(3,195)=160.75, p<.001\right)$. Using preliminary attitudes as a predictor of follow-up attitudes allows the effects of event participation to be isolated.

$<$ Table 3 here>

Participation in the informational events is also a significant predictor of follow-up attitudes $(B=2.770, p<.001)$, resulting in greater support for wind farms. I also added the interaction of event participation and preliminary attitudes to the model to see if the effects of event participation differed for people with different levels of preliminary support (figure 1). This analysis is important because average support for wind energy was quite high in this study. This interaction was negative and statistically significant $(B=-.604, p<.001)$. This means that the lower the preliminary enthusiasm of a participant, the greater the effect of participation on follow-up attitudes. In other words, participants with lower initial attitudes towards wind energy experienced greater changes in attitudes following participation in an informational event.

<Figure 1 here>

While these results suggest that participation in the information events influenced subsequent wind energy support for wind farms, other explanations should be considered. It is possible that ceiling effects on ratings of wind enthusiasm may be partly responsible for this interaction between prior levels 
of enthusiasm and post-event attitudes. Event participants exhibited a relatively high average level of enthusiasm ( $M=4.21)$ prior to the event; if they had already rated the items in this measure at the highest end of the scale, it would be impossible for their enthusiasm scores to rise in the follow-up survey. The participants with lower initial ratings had room to increase their score. The fact that those with the highest level of pre-test enthusiasm actually showed decreased ratings in the follow-up survey could also be attributed to a regression to the mean whereby random influences that pushed these people in a positive direction in the preliminary survey had a less positive influence in the follow-up survey. A final alternative explanation is that some event participants were less enthusiastic about commercial wind farm development after learning a bit more about the technology and siting process.

\section{Preliminary vs. Follow-Up Levels of Confidence}

Another separate stepwise regression model was developed to investigate the effects of preliminary confidence (a latent variable comprised of attitude-strength measures) and event participation on subsequent levels of confidence (table 4). In this study, preliminary confidence is a statistically significant predictor $(B=.640, p<.001)$ of follow-up confidence, explaining nearly 44 percent of the variance $\left(R^{2}=.436, F(3,195)=52.06, p<.001\right)$. Both the participation in an event $(B=1.341, p=.004)$ and the interaction of event participation with initial confidence were also significant $(B=-.339, p=.015)$. The interaction term means that the greater initial confidence, as measured in this study, the less event participation influenced follow-up confidence. Put another way, participants with a lower initial confidence score, on average, experienced a greater increase in this measure of attitude strength than those exhibiting higher initial confidence. As with the results for wind energy enthusiasm, it is possible that ceiling effects could influence these results.

$<$ Table 4 here> 
$<$ Figure 2 here $>$

\section{Discussion}

Consistent with other research on public attitudes towards renewable energy, the participants in this study exhibited quite high support for wind energy overall. As hypothesized, the results of this study suggest that participation in an information event can affect follow-up attitudes towards commercial wind energy. In this study, participation in events resulted in greater support for wind energy, on average, even though initial support was already quite high among the voluntary participants. Participation in the informational event had particularly large influence on those who were less enthusiastic towards wind farms prior to the event (figure 1). The research reported here also supports the notion that attending information events can strengthen attitudes. Consistent with my hypothesis, participation in events raised the average confidence of attitudes towards wind farm development in this study (figure 2). This was particularly true among those with lower initial confidence. A statistically significant interaction indicates that participants with higher initial levels of confidence experienced less change in confidence levels than those with lower initial ratings of confidence.

Because a small number of the invited residents voluntarily attended the information sessions, the findings of this study need to be reinforced by additional studies. Future studies on the impacts of information on general attitudes towards wind farms should focus on how contextual factors (e.g., economic conditions), individual differences in knowledge of renewable energy and wind farm technology, and the content of information programs influences the attitudinal outcomes. The content of the information programs may be a particularly interesting variable, as the team involved in the information programs for this study provided a balanced set of information and took care not to advocate a particular position regarding wind farm development. It would also be beneficial to 
understand how much the information itself contributed to changes in attitudes and confidence in those attitudes, versus how those changes were influenced by normative and social influences that come from interaction with fellow community members. These analyses should focus on how participants in information sessions perceive community norms and the norms of event participants. Perceived norms, even when those perceptions are inaccurate or in conflict, have been shown to have significant influence on behavior (Cialdini, 2003; Schroeder \& Prentice, 1998). Finally, it could be interesting to add additional attitude strength variables, beyond those that contribute to my measure of confidence. For example, items could be included to better understand the personal importance of energy issues to participants. This would allow for a more nuanced understanding of how providing information affects the structure of attitudes among participants. This current study does not tackle these important questions.

At the most basic level, however, the research reported here indicates that the role of information in shaping and changing attitudes towards wind energy should not be categorically dismissed. If the findings of this research hold true in other contexts, they could provide important insights into the role of information in wind farm siting.

What do the findings from this study suggest regarding the goal of informational interventions in wind energy siting cases? Based on the increase of information session participants' enthusiasm for wind energy in follow-up surveys, this research could be perceived as support for a deficit model framing of public attitudes. That is, proponents of wind energy could look to this study as evidence that information programs increase public support for wind farms among some participants. It is critical, however, to recognize that this study is focused on general attitudes towards commercial-scale wind development and not a specific project. As discussed in detail in the review of wind energy social science, general support for renewables or wind energy do not guarantee support for specific projects. In fact, information campaigns might result in a greater emphasis on conditional support of projects, as 
members of the public gain a more nuanced view of the benefits and costs of wind energy development. The nature of the project, the specific site selected, the siting process, and other factors could also contribute to public support or opposition of particular developments. Moreover, evidence that information can change public attitudes does not address the concerns voiced by scholars regarding the implications of a deficit-model framework on the treatment of public stakeholders. If anything, evidence that information can raise public support for commercial-scale wind farms could lead wind energy advocates to be more dismissive of public concerns. It is particularly important to stress that this study was conducted in a particular context and location, in communities with largely positive views towards wind energy; it would be short sighted to dismiss public concerns based on such a limited sample.

Reflecting a broader emphasis on deliberative engagement of public stakeholders in environmental decision making, a number of authors have endorsed the use of participatory processes the siting of wind farms and other renewables (Devine-Wright, 2011; Haggett, 2011). In principle, deliberative siting processes address concerns about a deficit-model framework by giving voice to members of the public holding diverse viewpoints about wind energy, its possible benefits to communities, and concerns about project siting and potential impacts. From this perspective, informational interventions should be focused on specific questions of the local public, with the goal of equipping members of the public to participate in participatory processes (Bell et al., 2005; Jones \& Eiser, 2009; Parks \& Theobald, 2011), rather than persuading them to support wind energy or a specific project. One should not lose sight, however, that receiving information may change the quality of attitudes held by the public, even if a change in support for a project is not anticipated or desired.

The potential of information to strengthen attitudes suggests another potential goal of providing information about renewables and wind energy: closing the social gap. General attitudes have greater influence on specific attitudes when the general attitudes are cognitively well developed (Eagly \& Chaiken, 1995; Eagly \& Kulesa, 1997). Weak attitudes are not expected to have substantial influence 
on other attitudes. As suggested by Van der Horst (2007), a lack of strength in general attitudes towards wind energy may provide a partial explanation for the inconsistency between general attitudes and attitudes towards specific wind energy developments. Given the nature of attitudinal structures, it is not unreasonable to expect that the consistency of general attitudes towards wind energy or renewables and responses to a specific wind farm proposal could be increased by strengthening general attitudes. As supported by the findings of this study, providing information to the public can strengthen general attitudes. Once again, this is no guarantee of greater support for specific projects, but it could reduce frustrations that stem from the oft-cited disconnect between positive public views of renewable technologies and public opposition to projects.

Admittedly, this study does not provide direct evidence that strengthening general attitudes will reduce the disparity between general public views towards renewables and attitudes towards specific projects. It does, however, demonstrate that, within this limited context, general attitudes towards renewables are changeable and can be "crystallized." More research is warranted on understanding how receiving information about wind energy in general influences attitudes about specific projects. A natural follow-up to the research reported in this article would be to track views towards a proposed wind farm project in a community where an information campaign or events have strengthened general attitudes among the residents.

With public policy encouraging growth in the contribution of renewable energy technologies to the supply of electricity, it is important that social science continue to investigate dynamics of public acceptance of these technologies. Researchers should continue to investigate the role that information plays in attitude information and attitude change. In particular, this study should be a call to environmental social scientists to consider issues of attitude strength and acknowledge that under some conditions informational interventions can influence the quality (i.e., strength) of attitudes as much as, if not more than, the degree of support for a project or action. In this regard, the study of wind energy 
projects would serve as a good laboratory for learning more about public acceptance of renewable technologies and other projects that face siting conflicts (Ellis et al., 2009).

\section{References}

Aitken, M. (2010). Why we still don't understand the social aspects of wind power: A critique of key assumptions within the literature. Energy Policy, 38, 1834-1841.

Ansolabehere, S., \& Konisky, D. M. (2009). Public attitudes toward construction of new power plants. Public Opinion Quarterly, 73(3), 566-577.

Barden, J., \& Petty, R. E. (2008). The mere perception of elaboration creates attitude certainty: Exploring the thoughtfulness heuristic. Journal of Personality and Social Psychology, 95(3), 489-509.

Bassili, J. N. (2008). Attitude strength. In W. . Crano \& R. Prislin (Eds.), Attitudes and attitude change (pp. 237-260). New York: Psychology Press.

Bauer, M. W., Allum, N., \& Miller, S. (2007). What can we learn from 25 years of PUS survey research? Liberating and expanding the agenda. Public Understanding of Science, 16(1), 79.

Bell, D., Gray, T., \& Haggett, C. (2005). The "social gap"in wind farm siting decisions: explanations and policy responses. Environmental Politics, 14(4), 460-477.

Bell, D., Gray, T., Haggett, C., \& Swaffield, J. (2013). Re-visiting the "social gap": public opinion and relations of power in the local politics of wind energy. Environmental Politics, 22(1), 115-135. doi:10.1080/09644016.2013.755793

Bidwell, D. (2013). The role of values in public beliefs and attitudes towards commercial wind energy. Energy Policy. Retrieved from http://www.sciencedirect.com/science/article/pii/S030142151300164X

Boninger, D. S., Krosnick, J. A., \& Berent, M. K. (1995). Origins of attitude importance: Self-interest, social identification, and value relevance. Journal of Personality and Social Psychology, 68(1), 61-61. 
Cass, N., \& Walker, G. (2009). Emotion and rationality: The characterisation and evaluation of opposition to renewable energy projects. Emotion, Space and Society, 2(1), 62-69.

Cialdini, R. B. (2003). Crafting normative messages to protect the environment. Current Directions in Psychological Science, 12(4), 105-109.

Crano, W. D., \& Prislin, R. (2006). Attitudes and persuasion. Annual Review of Psychology, 57, 345-374.

Devine-Wright, P. (2004). Beyond NIMBYism: towards an integrated framework for understanding public perceptions of wind energy. Wind Energy, 8(2), 125-139.

Devine-Wright, P. (2008). Reconsidering public acceptance of renewable energy technologies: a critical review. In M. Grubb, T. Jamasb, \& M. G. Pollitt (Eds.), Delivering a Low Carbon Electricity System: Technologies, Economics and Policy (pp. 443-461). Retrieved from http://geography.exeter.ac.uk/beyond_nimbyism/deliverables/Reconsidering_public_acceptanc e.pdf

Devine-Wright, P. (2009). Rethinking NIMBYism: The role of place attachment and place identity in explaining place-protective action. Journal of Community \& Applied Social Psychology, 19(6), 426-441.

Devine-Wright, P. (2011). Renewable energy and the public: From NIMBY to Participation. Washington, DC: Earthscan.

Devine-Wright, P. (2011). Public engagement with large-scale renewable energy technologies: breaking the cycle of NIMBYism. Wiley Interdisciplinary Reviews: Climate Change, 2(1), 19-26. doi:10.1002/wcc.89

Dillman, D. A., Smyth, J. D., \& Christian, L. M. (2009). Internet, mail, and mixed-mode surveys: The tailored design method (3rd ed.). Hoboken, N.J.: John Wiley and Sons. 
Eagly, A. H., \& Chaiken, S. (1995). Attitude strength, attitude structure, and resistance to change. In R. E. Petty \& J. A. Krosnick (Eds.), Attitude strength: Antecedents and consequences (pp. 413-432). Mahwah, NJ: Lawrence Erlbaum Associates, Inc.

Eagly, A. H., \& Kulesa, P. (1997). Attitudes, attitude structure, and resistance to change. In M. H. Bazerman, D. M. Messick, A. E. Tenbrunsel, \& K. A. Wade-Benzoni (Eds.), Environment, ethics, and behavior: The psychology of environmental valuation and degradation (pp. 122-153). San Francisco: The New Lexington Press.

Ek, K. (2005). Public and private attitudes towards "green" electricity: the case of Swedish wind power. Energy Policy, 33(13), 1677-1689. doi:10.1016/j.enpol.2004.02.005

Ellis, G., Barry, J., \& Robinson, C. (2007). Many ways to say "no", different ways to say "yes": applying QMethodology to understand public acceptance of wind farm proposals. Journal of Environmental Planning and Management, 50(4), 517-551.

Ellis, G., Cowell, R., Warren, C., Strachan, P., \& Szarka, J. (2009). Expanding wind power: A problem of planning, or of perception? Planning Theory and Practice, 10(4), 523-532.

Evans, G., \& Durant, J. (1995). The relationship between knowledge and attitudes in the public understanding of science in Britain. Public Understanding of Science, 4(1), 57-74.

Firestone, J., \& Kempton, W. (2007). Public opinion about large offshore wind power: Underlying factors. Energy Policy, 35(3), 1584-1598.

Gross, A. G. (1994). The roles of rhetoric in the public understanding of science. Public Understanding of Science, 3(1), 3-23.

Haggett, C. (2011). "Planning and persuasion": Pubic engagement in renewable energy decision-making. In P. Devine-Wright (Ed.), Renewable Energy and the Public (pp. 15-27). Washington, DC: Earthscan. 
Howell, R. A. (2014). Investigating the Long-Term Impacts of Climate Change Communications on Individuals' Attitudes and Behavior. Environment and Behavior, 46(1), 70-101.

Johansson, M., \& Laike, T. (2007). Intention to respond to local wind turbines: the role of attitudes and visual perception. Wind Energy, 10(5), 435-451.

Jones, C. R., \& Eiser, J. R. (2009). Identifying predictors of attitudes towards local onshore wind development with reference to an English case study. Energy Policy, 37(11), 4604-4614.

Kaldellis, J. K. (2005). Social attitude towards wind energy applications in Greece. Energy Policy, 33(5), 595-602.

Kasperson, R. E., \& Ram, B. J. (2013). The Public Acceptance of New Energy Technologies. Daedalus, 142(1), 90-96. doi:10.1162/DAED_a_00187

Kempton, W., Firestone, J., Lilley, J., Rouleau, T., \& Whitaker, P. (2005). The offshore wind power debate: Views from Cape Cod. Coastal Management, 33(2), 119-149.

Kollmuss, A., \& Agyeman, J. (2002). Mind the Gap: Why do people act environmentally and what are the barriers to pro-environmental behavior? Environmental Education Research, 8(3), 239-260. doi:10.1080/13504620220145401

Krohn, S., \& Damborg, S. (1999). On public attitudes towards wind power. Renewable Energy, 16(1), 954-960.

Krosnick, J. A., \& Abelson, R. P. (1992). The case for measuring attitude strength in surveys. In J. M. Tanur (Ed.), Questions about questions: inquiries into the coqnitive bases of surveys (pp. 177203). New York: Russel Sage Foundation.

Krosnick, J. A., \& Petty, R. E. (1995). Attitude strength: An overview. In R. E. Petty \& J. A. Krosnick (Eds.), Attitude strength: Antecedents and consequences (pp. 1-24). Mahwah, NJ: Erlbaum Associates. 
Lavine, H., Huff, J. W., Wagner, S. H., \& Sweeney, D. (1998). The Moderating Influence of Attitude Strength on the Susceptibility to Context Effects in Attitude Surveys. Journal of Personality and Social Psychology, 75(2), 359-373.

Lindeman, M. (2002). Opinion quality and policy preferences in deliberative research. In M. X. DelliCarpini, L. Huddy, \& R. Shapiro (Eds.), Research in Micropolitics: Political Decisionmaking, Deliberation and Participation (pp. 195-221). Greenwich, CT: JAI Press.

Nisbet, M. C., \& Scheufele, D. A. (2009). What's next for science communication? Promising directions and lingering distractions. American Journal of Botany, 96(10), 1767-1778.

Nolan, J. M. (2010). "An Inconvenient Truth" increases knowledge, concern, and willingness to reduce greenhouse gases. Environment and Behavior, 42(5), 643-658.

Owens, S. (2000). "Engaging the public": information and deliberation in environmental policy. Environment and Planning A, 32(7), 1141-1148.

Owens, S., \& Driffill, L. (2008). How to change attitudes and behaviours in the context of energy. Energy Policy, 36(12), 4412-4418.

Parks, J. M., \& Theobald, K. S. (2011). Public engagement with information on renewable energy developments: the case of single, semi-urban wind turbines. Public Understanding of Science. doi:10.1177/0963662511400962

Pasqualetti, M. J. (2011). Opposing wind energy landscapes: A search for common cause. Annals of the Association of American Geographers, 101(4), 907-917.

Petty, R. E., Haugtvedt, C. P., \& Smith, S. M. (1995). Elaboration as a determinant of attitude strength: Creating attitudes that are persistent, resistant, and predictive of behavior. In R. E. Petty \& J. A. Krosnick (Eds.), Attitude strength: Antecedents and consequences (Vol. 4, pp. 93-130). Hillsdale, NJ: Lawrence Erlbaum Associates, Inc. 
Pomerantz, E. M., Chaiken, S., \& Tordesillas, R. S. (1995). Attitude strength and resistance processes. Journal of Personality and Social Psychology, 69, 408-408.

Prislin, R. (1996). Attitude stability and attitude strength: One is enough to make it stable. European Journal of Social Psychology, 26(3), 447-477.

Schahn, J., \& Holzer, E. (1990). Studies of Individual Environmental Concern The Role of Knowledge, Gender, and Background Variables. Environment and Behavior, 22(6), 767-786. doi:10.1177/0013916590226003

Schroeder, C. M., \& Prentice, D. A. (1998). Exposing Pluralistic Ignorance to Reduce Alcohol Use Among College Students1. Journal of Applied Social Psychology, 28(23), 2150-2180.

Schultz, P. W. (2002). Knowledge, information, and household recycling: Examining the knowledgedeficit model of behavior change. New Tools for Environmental Protection: Education, Information, and Voluntary Measures, 67-82.

Strachan, P. A., \& Lal, D. (2004). Wind energy policy, planning and management practice in the UK: hot air or a gathering storm? Regional Studies, 38(5), 549-569.

Sturgis, P., \& Allum, N. (2004). Science in society: re-evaluating the deficit model of public attitudes. Public Understanding of Science, 13(1), 55-74.

Sturgis, P., Cooper, H., \& Fife-Schaw, C. (2005). Attitudes to biotechnology: estimating the opinions of a better-informed public. New Genetics and Society, 24(1), 31-56.

Swofford, J., \& Slattery, M. (2010). Public attitudes of wind energy in Texas: Local communities in close proximity to wind farms and their effect on decision-making. Energy Policy, 38(5), 2508-2519.

Szarka, J. (2006). Wind power, policy learning and paradigm change. Energy Policy, 34(17), 3041-3048.

Toke, D., Breukers, S., \& Wolsink, M. (2008). Wind power deployment outcomes: How can we account for the differences? Renewable and Sustainable Energy Reviews, 12(4), 1129-1147. 
Tuler, S. P., Ram, B., \& Kasperson, R. E. (2014). Wind Energy Facility Siting: Learning from Experience and Guides for Moving Forward. Wind Engineering, 38(2), 203-216.

Van der Horst, D. (2007). NIMBY or not? Exploring the relevance of location and the politics of voiced opinions in renewable energy siting controversies. Energy Policy, 35(5), 2705-2714.

Visser, P. S., Bizer, G. Y., \& Krosnick, J. A. (2006). Exploring the latent structure of strength-related attitude attributes. Advances in Experimental Social Psychology, 38, 1-67.

Walker, G. (1995). Renewable energy and the public. Land Use Policy, 12(1), 49-59. doi:10.1016/02648377(95)90074-C

Walker, G., Cass, N., Burningham, K., \& Barnett, J. (2010). Renewable energy and sociotechnical change: imagined subjectivities ofthe public'and their implications. Environment and Planning A, 42, 931-947.

Wolsink, M. (1989). Attitudes and expectancies about wind turbines and wind farms. Wind Engineering, 13(4), 196-206.

Wolsink, M. (2000). Wind power and the NIMBY-myth: institutional capacity and the limited significance of public support. Renewable Energy, 21(1), 49-64.

Wolsink, M. (2007). Wind power implementation: The nature of public attitudes: Equity and fairness instead of "backyard motives." Renewable and Sustainable Energy Reviews, 11(6), 1188-1207.

Wolsink, M. (2011). Discourses on the implementation of wind power: Stakeholder views on public engagement. In P. Devine-Wright (Ed.), Renewable Energy and the Public (pp. 15-27). Washington, DC: Earthscan.

Wolsink, M. (2012). Wind power: basic challenge concerning social acceptance. In Encyclopedia of Sustainability Science and Technology (Vol. 17, pp. 12218-12254). New York: Springer. Retrieved from http://dare.uva.nl/record/436899 
Wüstenhagen, R., Wolsink, M., \& Bürer, M. J. (2007). Social acceptance of renewable energy innovation: an introduction to the concept. Energy Policy, 35(5), 2683-2691.

Zaller, J., \& Feldman, S. (1992). A Simple Theory of the Survey Response: Answering Questions versus Revealing Preferences. American Journal of Political Science, 36(3), 579-616. doi:10.2307/2111583

Ziman, J. (1991). Public understanding of science. Science, Technology \& Human Values, 16(1), 99-105. 